\title{
Hijacked journals are emerging as a challenge for scholarly publishing
}

To the Editor Predatory journals are known to be a challenge for authors and, more generally, for scholarly publishing. These commercial journals are based on the pay-and-publish model ${ }^{1}$ and do not guarantee the quality of published papers as they are not peer-reviewed journals. Predatory journals boast a bogus impact factor to cheat the authors. ${ }^{2}$ Evidence on the activity of several predatory journals has been reported by academic researchers in different locations worldwide. Hijacked journals are another emerging challenge for scholarly publishing. In comparison with predatory journals, there is limited evidence on this journal phenomenon; however, the existing body of scientific evidence has been provided by leading scientists.

I had the opportunity to read the Letter to the Editor by Nieradko-Iwanicka, "Warning: hijacked journals", ${ }^{3}$ and I would like to discuss the phenomenon in more detail. Historically, the term "hijacked journals" was introduced to the academic world in early 2012 by Mehrdad Jalalian; indeed, the first attempt to hijack a journal was reported on August 11, 2011. ${ }^{4}$ Cybercriminals registered a domain "sciencerecord.com" for their dishonest and unfair publisher, which later became inactive. ${ }^{4}$ Using this approach, they hijacked 3 journals including Science Series Data Report, Innova Ciencia, and Science and Nature, alongside publishing 7 fake journals.

Clearly, there are differences between hijacked journals and faked ones. A hijacked journal has a fake website that mimics the website of a reputable, indexed journal; a fake journal has a fake name and unrecorded ISSN. ${ }^{4}$ The phenomenon of journal hijacking also affected the reliability and validity of medical research as hijackers published poor-quality studies in their hijacked journals. This was described by Jalalian in his scientific papers. ${ }^{5}$

Following Jalalian, we have also undertaken research on hijacked journals. We have termed the phenomenon of hijacked journals as "journal phishing". 6 The literature on information security defines a phishing attack as an attempt to steal sensitive information using fake websites. We found numerous similarities between phishing attacks and hijacked journals. Both use fake websites to cheat their victims. The websites are available for a short time, and false publishers send spam e-mails offering fast publication in impact factor journals to lure authors to submit their papers. We have investigated 90 known websites in search for hijacked journals and developed an algorithm for the detection of these journals. Our summarized algorithm is described below:

1 if the page ranking of the journal's website is lower than 4 , then the journal is suspected

2 if the journal's domain has been registered in the last 2 years, then it is suspected

3 in other cases, the journal's website is authentic.

The websites of hijacked journals are available for a short time and will be later removed by hijackers. Also, most hijacked domains had been registered a few months before the launch of hijacked websites. Thus, the domains of hijacked journals will not have high page ranking in search engines. In our approach, we used the Google page ranking (http://www.whatsmypr.net). In general, the domains of hijacked journals have low page ranking and have been registered in the last 2 years. This approach helps us identify hijacked journals, but not always. In fact, some authentic journals may change their website domains. The letter published in Pol Arch Med Wewn ${ }^{3}$ reported the hijacked version of the Ciencia e Tecnica Vitivinicola journal (http://ciencia-e-tecnica.org). The website of this hijacked journal has a page ranking equal to zero and was registered a year ago. Thus, according to the above approach, it is a hijacked journal.

There is no unique solution to the problem of hijacked journals. We need to develop a good educational and publishing plan as well as software tools for the detection of these journals. The number of hijacked, predatory, and fake journals will continue to grow so long as authors continue to submit their papers to them. Apart from these very questionable journals, other problems in scientific communication are emerging, such as fake conferences and bogus impact factors. 
Author names and affiliations Mehdi Dadkhah (Department of Computer and Information Technology, Foulad Institute of Technology, Fouladshahr, Isfahan, Iran); Claudia Stefanutti (Extracorporeal Therapeutic Techniques Unit, Lipid Clinic and Atherosclerosis Prevention Centre, Immunohematology and Transfusion Medicine; Umberto I Hospital, Department of Molecular Medicine; Sapienza University of Rome, Rome, Italy)

Corresponding author Mehdi Dadkhah, MSc, Department of Computer and Information Technology, Foulad Institute of Technology, Isfahan 8491663763, Fooladshahr, Shohada Blvd., Iran, phone: +989397379692, e-mail: dadkhah80@gmail.com

Conflict of interest The authors declare no conflict of interest.

\section{REFERENCES}

1 Clark J, Smith R. Firm action needed on predatory journals. BMJ. 2015; 350: h210.

2 Jalalian M. The story of fake impact factor companies and how we detected them. Electron Physician. 2015; 7: 1069-1072.

3 Nieradko-Iwanicka B. Warning: hijacked journals. Pol Arch Med Wewn. 2015; 125: 596

4 Jalalian M, Dadkhah M. The full story of 90 hijacked journals from $A u-$ gust 2011 to June 2015. Geographica Pannonica. 2015; 19: 73-87.

5 Jalalian M. Hijacked journals are attacking the reliability and validity of medical research. Electron Physician. 2014; 6: 925-926.

6 Dadkhah M, Sutikno T, Davarpanah Jazi M, Stiawan D. An Introduction to Journal Phishings and Their Detection Approach. TELKOMNIKA (Telecommunication, Computing, Electronics, and Control). 2015; 13: 373-380. 